\title{
Assessment of the Laurentian Great Lakes' hydrological conditions in a changing climate
}

\author{
Edouard Mailhot ${ }^{1,2}$ (D) Biljana Music ${ }^{1,3} \cdot$ Daniel F. Nadeau ${ }^{4} \cdot$ Anne Frigon $^{3}$. \\ Richard Turcotte ${ }^{2}$
}

Received: 21 November 2018 / Accepted: 14 August 2019 / Published online: 19 October 2019

(C) The Author(s) 2019

\begin{abstract}
A set of 28 simulations from five regional climate models are used in this study to assess the Great Lakes' water supply from 1953 to 2100 following emissions scenarios RCP4.5 and 8.5 with a focus on bi-weekly changes in the means and extremes of hydrological variables. Models are first evaluated by comparing annual cycles of precipitation, runoff, evaporation and net basin supply (NBS) with observations. Trends in mean values are then studied for each variable using Theil-Sen's statistical test. Changes in extreme conditions are analyzed using generalized extreme values distributions for a reference period (1971-2000) and two future periods (2041-2070 and 2071-2100). Ensemble trend results show evaporation increases of 136 and $204 \mathrm{~mm}$ (RCP4.5 and RCP8.5) over the Great Lakes between 1953 and 2100. Precipitation increases by 83 and $140 \mathrm{~mm}$ and runoff increases by 68 and $135 \mathrm{~mm}$. Trends are not equally distributed throughout the year as seasonal changes differ greatly. As a result, Great Lakes net basin supply is expected to increase in winter and spring and decrease in summer. Over the entire year, NBS increases of 14 and $70 \mathrm{~mm}$ are projected for scenarios RCP4.5 and 8.5 respectively by the year 2100 . An analysis of extreme values reveals that precipitation and NBS maxima increase by 11 to $27 \%$ and 1 to $9 \%$ respectively, while NBS minima decrease by 18 to $29 \%$ between $1971-2000$ and 2041-2100.
\end{abstract}

Ouranos, Université Laval

Electronic supplementary material The online version of this article (https://doi.org/10.1007/s10584-019-02530-6) contains supplementary material, which is available to authorized users.

Edouard Mailhot

Edouard.Mailhot@environnement.gouv.qc.ca

1 Université Laval, 1065, av. de la Médecine, Quebec, QC, G1V 0A6, Canada

2 Ministère de l'Environnement et de la Lutte contre les changements climatiques du Québec, 675 René-Lévesque Est, Quebec, QC, G1R 5V7, Canada

3 Ouranos - Consortium on Regional Climatology and Adaptation to Climate Change, 550 Sherbrooke West, West Tower, 19th Floor, Montreal, QC, H3A 1B9, Canada

4 Université Laval - Department of Civil and Water Engineering, 1065, av. de la Médecine, Quebec, QC, G1V 0A6, Canada 


\section{Introduction}

The Laurentian Great Lakes' region, spanning close to $780,000 \mathrm{~km}^{2}$, is home to some 40 million people and hosts economic activities worth hundreds of billions of dollars each year (MacKay and Seglenieks 2013). In this context, anticipating how climate change may alter the water balance of the lakes in the decades to come is of the utmost importance (Gronewold et al. 2013). In doing so, past studies have focused on estimating net basin supply $(N B S)$ as a main driver of lake levels (Croley 1990; Hartmann 1990; Lofgren et al. 2002; Deacu et al. 2012; MacKay and Seglenieks 2013; Music et al. 2015). NBS represents the simplified hydrological balance of a lake, expressed as a water depth, such that

$$
N B S=P_{\text {lake }}+R_{\text {land }}-E_{\text {lake }},
$$

where $P_{\text {lake }}$ is the over-lake precipitation, $R_{\text {land }}$ is the land runoff, and $E_{\text {lake }}$ is the lake evaporation. The balance presented in Eq. 1 is the so-called component method. Other approaches exist, such as the residual method (see Deacu et al. 2012), but they will not be explored in this paper.

The first climate change studies focusing on the hydrology of the Great Lakes region have applied the change factor method to explore how climate variables linked to the evaluation of Eq. 1 would evolve throughout the twenty-first century (Croley 1990; Hartmann 1990; Angel and Kunkel 2010). By using two offline hydrologic models (one for the lakes and one for the land), this method consists of adjusting observations by either adding the difference or multiplying the ratio between future and historical climate runs to produce new, perturbed time series. Then, the latter are used as inputs in the Advanced Hydrological Prediction System (AHPS; see Gronewold et al. 2011 for an appraisal of this system) to obtain projections for the Great Lakes NBS. In doing so, most studies relying on Global Circulation Models (GCMs) have reported decreases in NBS ranging from 23 to $51 \%$ (Croley 1990), translating into declines of lake levels between 20 and $250 \mathrm{~cm}$ (Hartmann 1990) by the end of the twenty-first century.

More recently, Lofgren et al. (2011) raised the issue that the hydrological model used in AHPS lacked any constraint for conservation of energy at the earth's surface. As a result, evapotranspiration (computed using temperature-based equations) was likely overestimated and runoff underestimated, leading to artificial drops in future net basin supply. Lofgren et al. (2013) argued that using hydrological outputs from climatic models directly would circumvent this issue as energy and water conservation is ensured by the model itself.

Within climate models, the vertical transport of heat and momentum between open water surfaces and the atmosphere can be simulated by a lake model, whose role is to capture the lake thermal regime and its ice cover. Lake schemes of various complexity have been proposed over the years, ranging from 1D simple models (used in MacKay and Seglenieks 2013 ) to two-way coupled 3D models fully resolving the lake hydrodynamics (Xue et al. 2017). No matter its complexity, a lake model should ideally be coupled to the climate model to allow for two-way exchanges of heat, momentum and water.

Unfortunately, most of previous studies either lacked a lake model (Deacu et al. 2012) or used one in an offline mode (such as the AHPS, used in Angel and Kunkel (2010)). Regional Climate Models (RCMs), on the other hand, provide energy and water conservation in addition to resolving smaller-scale processes given their high spatial resolution (typically 25-45 $\mathrm{km}$ versus $\sim 200 \mathrm{~km}$ for GCMs). As a result, a better representation of feedback processes and a finer hydrological sensitivity can be attained (Wood et al. 2004; Leung et al. 2004). As such, recent studies relying on RCMs and coupled lake models have reported much less dramatic declines in NBS (e.g., MacKay and Seglenieks 2013; Music et al. 2015; Notaro 
et al. 2015). A comparison between the 1962-1990 and 2021-2050 periods revealed NBS changes between -9 and $+1 \%$ depending on the lake, and small water level decreases ranging from 3 to $6 \mathrm{~cm}$ (MacKay and Seglenieks 2013). Music et al. (2015) obtained an ensemble median of $0 \mathrm{~mm}$ day $^{-1}$ for NBS changes between 1971-1999 and 2041-2070 for lake Michigan-Huron.

In recent years, the Coordinated Regional Climate Downscaling Experiment for North America (NA-CORDEX; Mearns et al. 2017) coordinated the production of regional downscaled climate projections to support impact assessment studies over the continent. Using this project's newest generation of RCM makes this study relevant as it updates the results of older hydrological studies focusing on the Great Lakes region. Along with recent models, representative concentration pathways (RCPs) are used instead of previously applied scenarios from the Special Report on Emissions Scenarios (SRES; e.g., Angel and Kunkel 2010; Hayhoe et al. 2010; Music et al. 2015).

This paper also innovates by downscaling to 2 weeks the time period for which the analyses are made. Doing this will increase our understanding of climate change impacts within a monthly time threshold that was used in previous analyses (e.g., Notaro et al. 2015). This time scale is also more appropriate to the study of extreme events that were previously assessed using monthly time series (Music et al. 2015).

The objective of this paper is to report impacts of climate change on mean and extreme values of the Great Lakes NBS and its components using a set of RCM models, emissions scenarios and driving GCMs to better account for various sources of uncertainty.

\section{Methods}

\subsection{Models and data}

The plausible range of changes in NBS components are derived from five NA-CORDEX RCMs whose simulations recently became available (see NA-CORDEX website). Table 1 presents the name, modeling institute, driving GCM, spatial resolution, emissions scenario, and lake model of each simulation. The RCMs are CanRCM4 (Scinocca et al. 2016), CRCM5-Ouranos, CRCM5-UQAM (for both versions of CRCM5, see Martynov et al. (2013) and Šeparović et al. (2013)), HIRHAM5 (Christensen et al. 2006), and RCA4 (Kupiainen et al. 2011). Models will be referred to using the abbreviations in the first column of Table 1.

Three of the five RCMs (22 out of 28 simulations) are coupled to FLake, a 1D lake model that uses a parametric representation of the changing temperature profiles inside a two-layer system while also taking into account the energy budget inside the mentioned layers (Golosov et al. 1441). FLake was developed by Mironov et al. (2003) and has been successfully used in RCMs and GCMs (e.g., Samuelsson et al. 2010; Martynov et al. 2012).

When an RCM does not include a lake model (CanRCM4 and HIRHAM5), the Great Lakes' characteristics (surface temperature, ice cover, etc.) are imported from the nearest lake tile of the driving GCM.

All RCM runs are generated over the CORDEX North American domain at a spatial resolution of $0.22^{\circ}$ or $0.44^{\circ}(\sim 25$ or $\sim 50 \mathrm{~km})$. They are all driven by a GCM except for one of the five CRCM5-O runs, which is driven by the ERA-Interim reanalysis. Given the focus of the paper, only model outputs located within the Great Lakes Basin are considered. Figure 1 presents the basin with the model tiles of CRCM5-O (spatial resolution, $0.22^{\circ}$ ) represented as dots. Note that lakes Michigan and Huron are considered as a single entity 
Table 1 List of regional climate models used in this study for the period 1953-2100

\begin{tabular}{|c|c|c|c|c|c|}
\hline $\mathrm{RCM}$ & Institute & Driving GCM & Spatial resolution & $\begin{array}{l}\text { Emissions } \\
\text { scenario }\end{array}$ & $\begin{array}{l}\text { Lake } \\
\text { model }\end{array}$ \\
\hline \multirow[t]{3}{*}{ CanRCM4 } & \multirow[t]{3}{*}{ CCCma } & \multirow[t]{3}{*}{ CanESM2 } & \multirow[t]{3}{*}{$0.22^{\circ}$} & historical & \multirow[t]{3}{*}{ None } \\
\hline & & & & $\mathrm{RCP} 4.5$ & \\
\hline & & & & RCP8.5 & \\
\hline \multirow[t]{12}{*}{ CRCM5-O } & \multirow[t]{12}{*}{ Ouranos } & \multirow[t]{3}{*}{ CanESM2 } & \multirow[t]{3}{*}{$0.22^{\circ}$} & historical & \multirow[t]{12}{*}{ FLake } \\
\hline & & & & RCP4.5 & \\
\hline & & & & RCP8.5 (5) & \\
\hline & & \multirow[t]{3}{*}{ CNRM-M5 } & \multirow[t]{3}{*}{$0.22^{\circ}$} & historical & \\
\hline & & & & $\mathrm{RCP} 4.5$ & \\
\hline & & & & RCP8.5 & \\
\hline & & \multirow[t]{3}{*}{ GFDL-ESM2M } & \multirow[t]{3}{*}{$0.22^{\circ}$} & historical & \\
\hline & & & & RCP4.5 & \\
\hline & & & & RCP8.5 & \\
\hline & & \multirow[t]{2}{*}{ MPI-ESM-LR } & \multirow[t]{2}{*}{$0.22^{\circ}$} & historical & \\
\hline & & & & RCP8.5 & \\
\hline & & ERA-Interim & $0.22^{\circ}$ & reanalysis & \\
\hline \multirow[t]{4}{*}{ CRCM5-U } & \multirow[t]{4}{*}{ UQAM } & \multirow[t]{2}{*}{ CanESM2 } & \multirow[t]{2}{*}{$0.44^{\circ}$} & historical & \multirow[t]{4}{*}{ FLake } \\
\hline & & & & $\mathrm{RCP} 4.5$ & \\
\hline & & \multirow[t]{2}{*}{ MPI-ESM-LR } & \multirow[t]{2}{*}{$0.44^{\circ}$} & historical & \\
\hline & & & & RCP4.5 & \\
\hline \multirow[t]{3}{*}{ HIRHAM5 } & \multirow[t]{3}{*}{ DMI } & \multirow[t]{3}{*}{ EC-EARTH } & \multirow[t]{3}{*}{$0.44^{\circ}$} & historical & \multirow[t]{3}{*}{ None } \\
\hline & & & & $\mathrm{RCP} 4.5$ & \\
\hline & & & & RCP8.5 & \\
\hline \multirow[t]{6}{*}{ RCA4 } & \multirow[t]{6}{*}{ SHMI } & \multirow[t]{3}{*}{ CanESM2 } & \multirow[t]{3}{*}{$0.44^{\circ}$} & historical & FLake \\
\hline & & & & RCP4.5 & \\
\hline & & & & RCP8.5 & \\
\hline & & EC-EARTH & $0.44^{\circ}$ & historical & \\
\hline & & & & RCP4.5 & \\
\hline & & & & RCP8.5 & \\
\hline
\end{tabular}

A total of 28 simulations are analyzed. The RCP8.5 CRCM5-O simulation driven by CanESM2 is an ensemble of 5 runs. The reanalysis run extends from 1979 to 2014. Institutes are the Canadian Centre for Climate Modelling and Analysis (CCCma), the University of Quebec in Montreal (UQAM), the Danish Meteorological Institute (DMI), and the Swedish Meteorological and Hydrological Institute (SHMI)

given that their water levels are, on average, roughly the same over long periods. Only outputs of precipitation and evaporation over lake tiles are included in the analysis since NBS is computed over a lake. Runoff values, taken on land tiles, are multiplied by the ratio of lake to land surface areas of a particular watershed so that they represent a water depth over a lake, allowing the computation of NBS values.

RCPs 4.5 and 8.5 are used as greenhouse gas concentration scenarios for the simulations in this study. Numbers represent increases in radiative forcing $\left(\mathrm{W} \mathrm{m}^{-2}\right)$ in 2100 relative to pre-industrial values. 


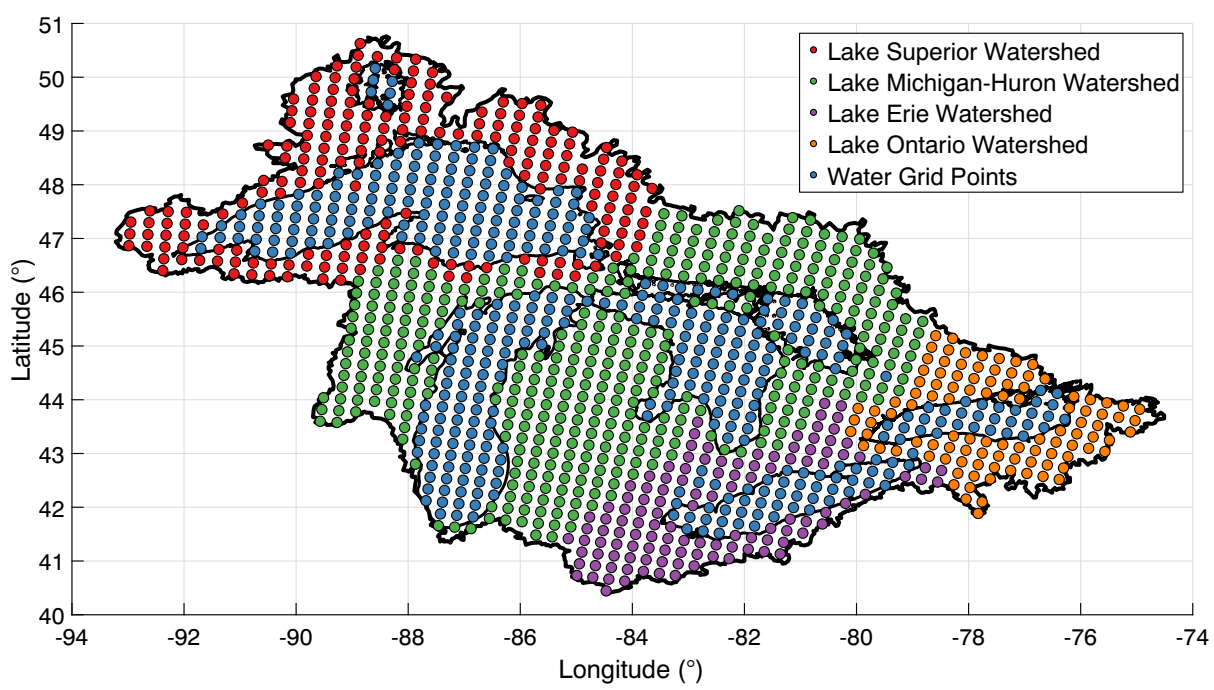

Fig. 1 Great Lakes Basin with CRCM5-O grid points indicated by colored dots. Blue dots represent 100\% lake tiles

\subsection{Validation}

A comparison with the Large Lake Statistical Water Balance Model (L2SWBM; Gronewold et al. 2016) from the Great Lakes Environmental Research Laboratory (GLERL) is undertaken to evaluate climate model outputs. L2SWBM results from an effort to combine measurement-based estimates with models while closing the Laurentian Great Lakes water balance. Furthermore, advanced statistical methods are used in order to take into account the measurements' uncertainties. The 1970-2000 period is selected to validate the models. Although identifying RCM biases is key, it will not greatly impact the analysis as we assume that the biases will partially cancel out when computing climate change signals.

\subsection{Trend analysis}

Trends within the RCM datasets are estimated with the Theil-Sen statistical test (Theil 1950; Sen 1968) over the study period. This test, often used in climate change studies (Zhao et al. 2010; Some'e et al. 2012), allows for the determination of a line passing through sample points that minimizes the distances between data points and the produced linear regression. The test is similar to the simple linear regression but is less sensitive to outliers and often deemed more robust (Wilcox 2001). The data points through which the regression is made are bi-weekly mean averaged over the Great Lakes with February 29ths and December 31 sts removed from the dataset (so as to create standard 364-day years). The resulting Theil-Sen slope estimators have units of $\mathrm{mm} \mathrm{day}^{-1} \mathrm{year}^{-1}$. By multiplying them by the number of days in a two-week period and by the number of years in the study period (i.e., 148), the slopes can be converted to absolute changes from 1953 to 2100 with units of $\left[\mathrm{mm}\left\{14\right.\right.$ days $\left.^{-1}\right]$. The Theil-Sen approach is used here to explore trends in the 148-year long time-series, thus making it less vulnerable to natural variability than the traditional delta method. Indeed, when computing the Theil-Sen estimator, model outputs from 1953 
to 2100 are used whereas only part of the data are included when comparing periods using the delta approach.

\subsection{Extreme values analysis}

Along with an analysis of the average hydrological conditions, it is also relevant to assess possible changes in the highest and lowest values for 2 -week periods. To do this, bi-weekly annual time series of minima/maxima (i.e., the highest and lowest values over a period of 14 consecutive days for each year) are built to cover three time periods (i.e., 1971-2000, 20412070, and 2071-2100) for NBS and its components. As such, 30 minima and 30 maxima are gathered for each of the three periods. To compare differences between reference and future years, a generalized extreme values (GEV) distribution, commonly used in this type of study (Kharin and Zwiers 2005; Tramblay et al. 2012), is fitted to each dataset of 30 combined minima and maxima for each 30-year period. Minimum and maximum 14-day values of daily averages with return periods of 10 and 50 years are then identified using the estimated parameters. The temporal changes in return periods are then analyzed to explore the evolution of extreme hydrological events in the Great Lakes region.

\section{Results}

\subsection{Validation}

Figure 2 presents the annual cycle of NBS and its components for the validation period. As seen in Fig. 2a, over-lake precipitation has the annual cycle with the lowest variance throughout the year with values contained within a $100 \mathrm{~mm}^{\mathrm{month}}{ }^{-1}$ interval. The simulations are thus in relative agreement with each other. The RCM ensemble mean has a positive bias of $124 \mathrm{~mm}(+19 \%)$ over the whole year when compared with L2SWBM data. Seasonally, the overestimation is greater in winter and spring, with the maximal overestimation of the ensemble reaching $19.2 \mathrm{~mm}$ in March. HIRHAM5 significantly overestimates precipitation during spring and summer months with differences of up to $35.8 \mathrm{~mm} \mathrm{month}^{-1}$.

Simulations from CRCM5 all follow a similar cycle for land runoff expressed over the lakes. As is shown in Fig. 2b, runs from this RCM, although having higher values than L2SWBM for the spring peak, reproduce adequately the measurement-based annual cycle. Other RCMs do not perform as well. Indeed, CanRCM4 and RCA4 values remain below the L2SWBM data for almost all months. The ensemble mean has a small bias of $3 \%$ over the whole annual cycle. Monthly ensemble biases, on the other hand, oscillate between $22 \%$ $\left(17.1 \mathrm{~mm} \mathrm{month}^{-1}\right)$ in June and $-40 \%\left(-18.8 \mathrm{~mm} \mathrm{month}^{-1}\right)$ in October.

The lake evaporation annual cycle produced with the observation-based estimates from L2SWBM has a different pattern than most model outputs. Indeed, Fig. 2c shows that, starting in spring, observations and the RCM ensemble differ by up to $50 \mathrm{~mm} \mathrm{month}^{-1}$ in their 1970-2000 monthly means. CRCM5 simulations overestimate evaporation in summer and display a maxima in October rather than in December while RCA4 ones peak in August. Both have FLake as their lake model and warmer water temperatures (not shown) may be responsible for the disparity with the validation data.

HIRAM5 displays a very different pattern from the other simulations and the observation-based data set. It shows very little variance in the annual cycle of evaporation which leads to important underestimates of 65 and $67.4 \mathrm{~mm} \mathrm{month}^{-1}$ for October and 

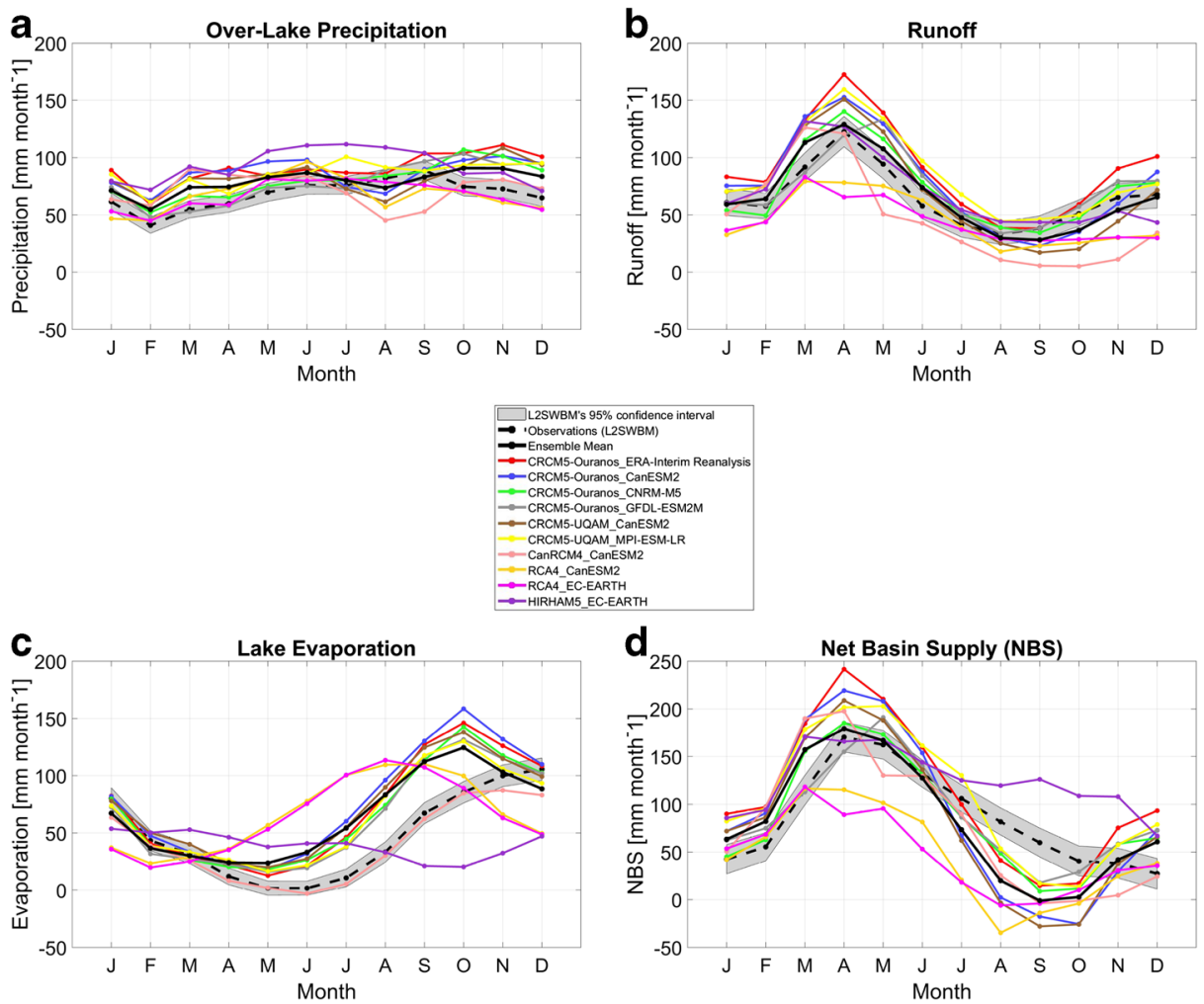

Fig. 2 Validation of over-lake precipitation (a), land runoff expressed over the lakes (b), lake evaporation (c), and NBS (d) for the Great Lakes watershed over the 1970-2000 period using annual cycles of monthly means. The period for the reanalysis dataset is 1978-2000. The ensemble mean does not include HIRHAM5

November respectively. The absence of a lake model in HIRHAM5 and its dependence on EC-EARTH seem to be causing the behavior. Recall that lake surface conditions (e.g., surface temperature and ice cover) over each lake grid tile of this RCM are derived from the driving model's nearest lake tile. In the case of evaporation, this method leads to poor validation results for HIRHAM5. The other simulation using EC-EARTH (with RCA4 as the $\mathrm{RCM}$ ) has a very different behavior because it uses FLake to obtain lake surface conditions. Finally, CanRCM4 shows excellent results as it closely follows observations. Overall, the ensemble mean overestimates lake evaporation for almost all months, with a total annual bias of $207.4 \mathrm{~mm}(+27 \%)$.

Figure 2d presents the NBS validation. Annual cycles display similar patterns for most simulations, and are characterized by a mean ensemble peak of $179.3 \mathrm{~mm}$ month $^{-1}$ in April due to snowmelt runoff and a subsided period in late summer and early fall in which the lowest ensemble value reaches $-1 \mathrm{~mm}^{\text {month }}{ }^{-1}$ in September. All models, other than HIRHAM5, show significant NBS negative biases of up to $-120 \mathrm{~mm} \mathrm{month}^{-1}$ in summer and fall. Overall, the sum of biases results in an annual difference of $-56.8 \mathrm{~mm}$ when compared to L2SWBM but single month biases can go as high as $42.5 \mathrm{~mm} \mathrm{month}^{-1}$ in March and as low as $-61.9 \mathrm{~mm} \mathrm{month}^{-1}$ in August. 
It is interesting to note the performance of the CRCM5 run driven by the ERA-Interim reanalysis. It is not, as expected, the closest to the observations but instead shows a similar behavior to the other CRCM5 simulations. This suggests that the RCM and lake model, common to these runs, influence outputs more heavily than the driving GCMs do.

HIRHAM5 is excluded from the rest of the study due to its significant differences with the validation data for precipitation, evaporation and NBS. This RCM does not seem to be able to model the processes of evaporation in the Great Lakes adequately. It is believed that a model without this ability cannot reliably be used to estimate future changes in NBS. Other RCMs achieve satisfactory results and will aid in assessing future hydrological changes of the Great Lakes.

\subsection{Trend analysis: changes in mean hydrological conditions}

The trend analysis for the average conditions of NBS and its components is presented in Figs. 3 (RCP4.5) and 4 (RCP8.5). The points indicating changes close to a value of 0 have a small statistical significance. For steeper Theil-Sen slopes, where points are further away from 0 , the significance is greater. Statistically significant results with confidence levels of $97.5 \%$ generally start with negative and positive changes of $7 \mathrm{~mm}(14 \text { days })^{-1}$.

As seen in Fig. 3a, RCP4.5 simulations, as an ensemble, show a rise of $83 \mathrm{~mm}$ in overlake precipitation for the whole year when comparing climates from 1953 and 2100. On the other hand, a 140-mm increase is found over the Great Lakes using the more pessimistic RCP8.5 scenario. Precipitation gains are not evenly distributed throughout the year. Indeed, the four months between January and June contribute 68\% (RCP4.5) and 74\% (RCP8.5) of the annual increases. In both cases, the summer months show no important changes while increases re-appear in the fall. Results agree with past studies in which positive trends in over-lake precipitation were found for the same region (e.g., Music et al. 2015; Notaro et al. 2015).

Land runoff changes are similar in magnitude to those of precipitation, but the increases are seen in winter (see Figs. $3 \mathrm{~b}$ and $4 \mathrm{~b}$ ). Winter increases are caused by warmer air temperatures which transform a fraction of the precipitation from a solid to a liquid state, thus inducing greater runoff.

Temperature increases also have the effect of reducing snow water equivalent (SWE), as seen in Fig. 5, and shortening the duration of the snow cover by approximately a month. SWE mean annual maxima for RCP4.5 and 8.5 are lowered by 20 and $26 \mathrm{~mm}$ respectively between 1970-2000 and 2070-2100 (-42\% and -57\%). These phenomena contribute to increased winter runoff across the Great Lakes watershed. The RCP4.5 ensemble runoff changes over the whole annual cycle represent a 68 -mm increase, which is mostly attributable to the winter months. Figure 4 b shows a similar pattern but with steeper trends for RCP8.5 as an annual increase of $135 \mathrm{~mm}$ is projected.

A look at panels (c) of Figs. 3 and 4 shows positive lake evaporation trends all year long for both ensembles with only a few occurrences of declines for single simulations. Although average trends are positive for all 2-week periods, they are more important in summer months. Indeed, $62 \mathrm{~mm}$ of the total annual increase of $136 \mathrm{~mm}(46 \%)$ happens during summer for RCP4.5, while summer increases represent 91 of $204 \mathrm{~mm}$ (45\%) for scenario RCP8.5. Compared with net annual increases of other variables, the Theil-Sen slope estimators for evaporation are steeper. Lake evaporation is thus the NBS component most affected by climate change. 

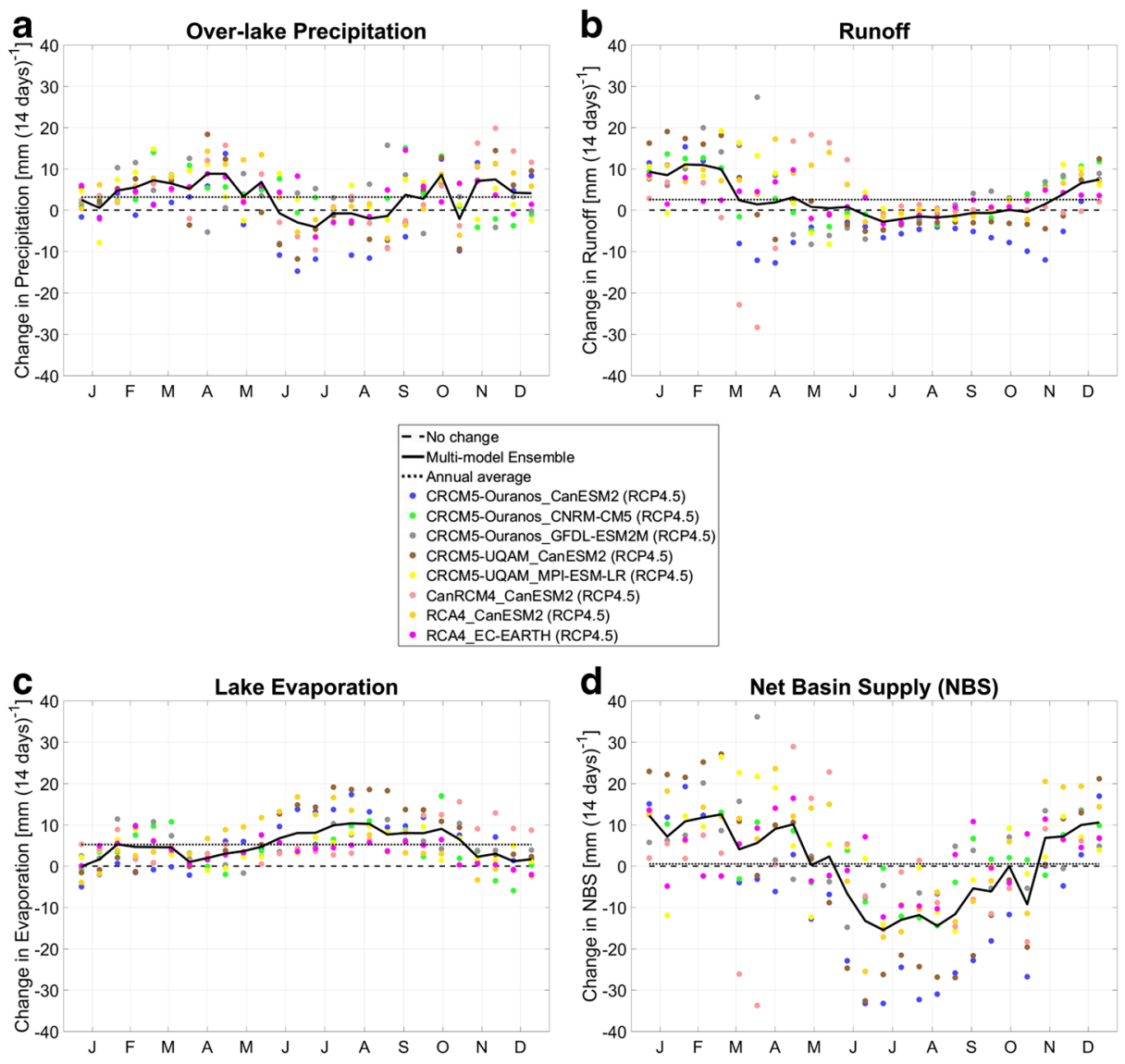

Fig. 3 Trends in bi-weekly a over-lake precipitation, b land runoff expressed over the lakes, $\mathbf{c}$ lake evaporation, and d NBS for the Great Lakes over the 1953-2100 period based on Theil-Sen estimators from RCP4.5 simulations

Changes in NBS are shown in Figs. $3 d$ and $4 d$. There is a large variability among the trends computed from model outputs. The variability found for each component is propagated to the water budget since NBS is the sum of land runoff and over-lake precipitation minus lake evaporation. Even with this larger range of changes, a clear pattern emerges from the data. Increases in precipitation and runoff are found to cause positive NBS changes during winter and spring, whereas increases in evaporation cause negative NBS trends in summer. Bi-weekly NBS changes range from an increase of $13 \mathrm{~mm}$ in early March to a decrease of $15 \mathrm{~mm}$ in early July for RCP4.5. For RCP8.5, they range from a rise of $21 \mathrm{~mm}$ in late April (a similar increase of $20 \mathrm{~mm}$ is also found in early February) to a decline of $18 \mathrm{~mm}$ in early September. The winter maximum is caused by the increase in land runoff, whereas the subsequent spring peak value is a consequence of changes in precipitation. Finally, the longer period of NBS decrease during summer and early fall results from important increases in lake evaporation. A small positive change of $14 \mathrm{~mm}$ is obtained for RCP4.5 

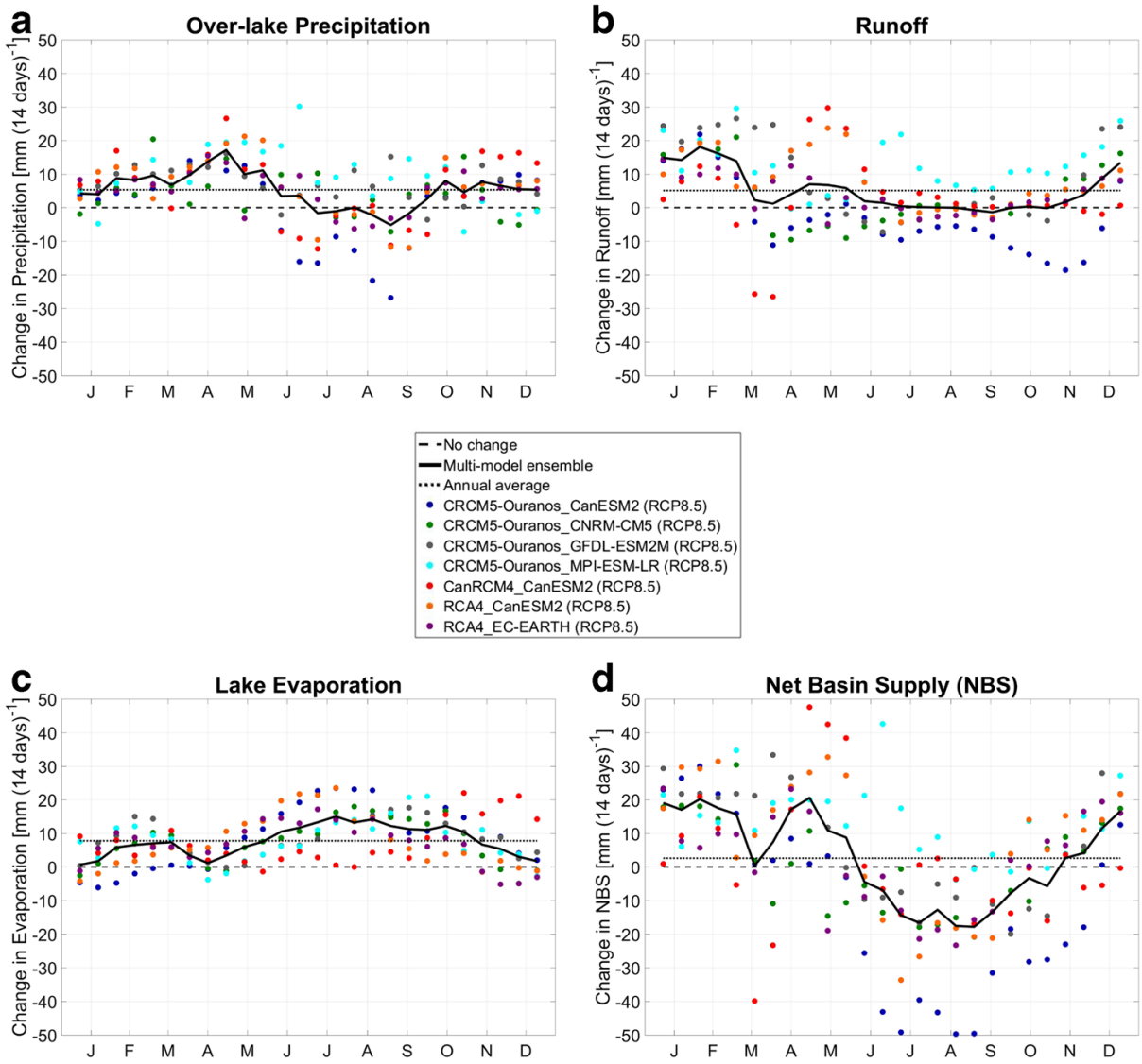

Fig. 4 Trends in bi-weekly a over-lake precipitation, $\mathbf{b}$ land runoff expressed over the lakes, $\mathbf{c}$ lake evaporation, and d NBS for the Great Lakes over the 1953-2100 period based on Theil-Sen estimators from RCP8.5 simulations

and an increase of $70 \mathrm{~mm}$ for RCP8.5 for the whole year. The RCP4.5 change represents a relative increase of $1.7 \%$ when compared with NBS values of the ensemble's historical runs from the 1970-2000 period. In the same manner, the RCP8.5 change is an increase of $9.2 \%$. The conclusion that lake levels will not undergo drastic changes annually can be reached without even running hydraulic routing models such as GLERL's Hydrologic Response Model (HRM; Quinn 1978) to generate lake level values using the projected NBS time series. Changes will rather be felt on a seasonal basis since summer and fall results differ greatly from spring and summer ones.

Additional figures showing the results for individual lakes are presented in the Supporting Information document. Among the most obvious differences between the lakes, one can notice the important winter increase in runoff values for Lake Ontario and the significant increase of evaporation, also in winter, for Lake Superior.

For the Great Lakes as a whole, we expect an amplification of the annual cycles of lake evaporation and NBS for both emissions scenarios. Lake evaporation increases will occur mostly during summer and fall. This latter season is, historically, the one in which observations show the highest values (see Fig. 2c and Spence et al. 2013). Similarly, the NBS 

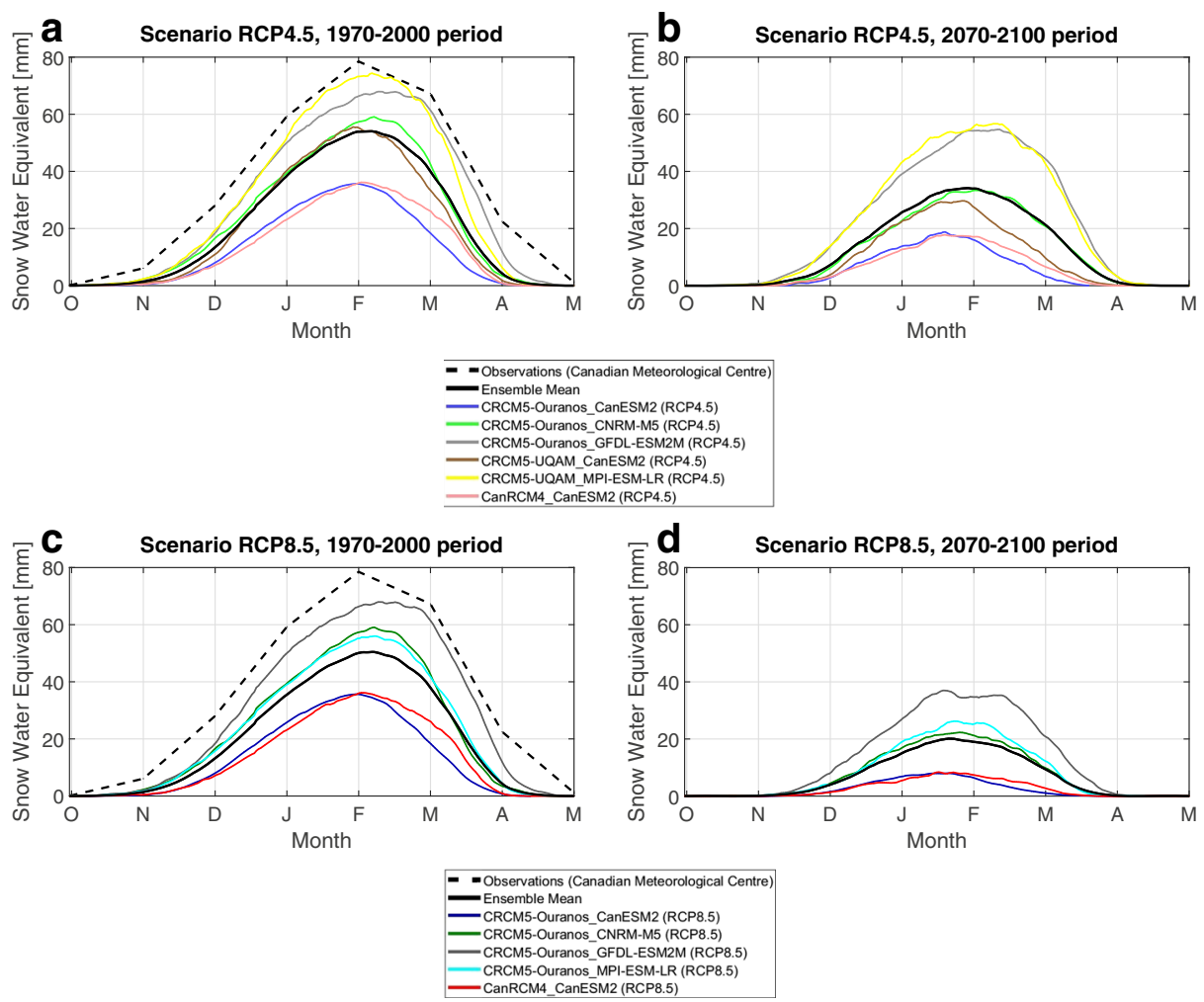

Fig. 5 Evolution of snow water equivalent across the Great Lakes watershed for scenario RCP4.5 in a 19702000 and b 2070-2100 and for scenario RCP8.5 in c 1970-2000 and d 2070-2100. Observed data produced by the Canadian Meteorological Centre (Brown et al. 2003) for the 1979-1996 period

cycle is amplified by the projected changes since increases are expected to occur during the spring when NBS values are already high, while decreases occur during the summer when values are historically the lowest (Fig. 2d).

Results of small positive annual increases in NBS (2 and 9\%) strongly contrast with earlier studies based on the change factor method in which negative NBS changes of 23 to $51 \%$ (Croley 1990) and lake level drops of 20 to $250 \mathrm{~cm}$ (Hartmann 1990) were reported. The methodology, and now, the results of the trend analysis, bring this study more in line with studies based on RCMs. In those, NBS changes from 1976 to 2036 vary between -9 and $+1 \%$ (MacKay and Seglenieks 2013). The seasonal amplification of the evaporation and NBS cycles is also distinctive of the RCM approach to the assessment. Music et al. (2015) and Notaro et al. (2015) both obtained the highest evaporation increases between July and October. In addition, both found amplified NBS cycles due to increases between November and March and declines from May to October. In the case of change factor studies, the NBS decreases were scattered evenly throughout all seasons (Croley 1990) causing lake level drops to remain close to, in Hartmann (1990) for example, $120 \mathrm{~cm}$ all year long for lake Erie for one simulation between 1981 and 2060. For a brief review of past and present results, see Fig. 6. Please note that the compared studies do not use the same time period or physical scope for their analyses, but a comparison remains of value nonetheless. Now that 
conclusions of the trend analysis have been compared with past studies, the results of the analysis of extreme events will continue the assessment at hand.

\subsection{Extreme values analysis}

Figure 7 presents the outcomes of the extreme values analysis for scenario RCP4.5, while results for RCP8.5 are shown in Fig. 8. As seen in Figs. 7a and 8a, there is a large uncertainty in projected changes of daily precipitation minima. RCP4.5 leads to a small decline while RCP8.5 indicates no change according to the ensemble means. For maxima (b), daily precipitation return levels increase when comparing future periods with 1971-2000 for both scenarios. Increases of 0.7 to $1.7 \mathrm{~mm} \mathrm{day}^{-1}$ (11 to $25 \%$ ) with higher percentages for the 2041-2070 period are observed for RCP4.5 while increases of 0.9 to $1.8 \mathrm{~mm} \mathrm{day}^{-1}$ (15 to $27 \%$ ) are projected for RCP8.5.

NBS results are presented in Figs. $7 \mathrm{c}$ and $\mathrm{d}$ and $8 \mathrm{c}$ and $\mathrm{d}$. Minima tend to decrease while maxima tend to increase by small increments for both scenarios. Minimum values associated with 10- and 50-year return periods for this variable decrease by 0.6 to $1.0 \mathrm{~mm} \mathrm{day}^{-1}$ (18 to $26 \%$ ) for RCP4.5 and by 0.7 to $1.1 \mathrm{~mm} \mathrm{day}^{-1}$ (18 to $29 \%$ ) for RCP8.5. Maximum values increase by 0.1 to $0.3 \mathrm{~mm} \mathrm{day}^{-1}$ ( 1 to $3 \%$ ) for RCP4.5 and by 0.1 to $1.2 \mathrm{~mm} \mathrm{day}^{-1}$ ( 1 to $9 \%$ ) for RCP8.5. Values given here are, as mentioned previously, annual bi-weekly NBS minima/maxima for the entire Great Lakes.

As is quite noticeable, changes worsen the extreme conditions of the reference period. Over-lake precipitation maxima get more extreme, NBS minima decrease and NBS maxima increase in future periods. This is coherent with the results presented in Section 3.2 which emphasized the projected aggravation of the annual cycles by climate change.

Precipitation results are coherent with Notaro et al. (2015) who found increases in precipitation intensity. In their study, the 100-year precipitation quantile was found to increase by 7 to $8 \%$ by the end of the 21 th century, while our analysis suggests an increase of $11-27 \%$ for maxima of 14-day periods.

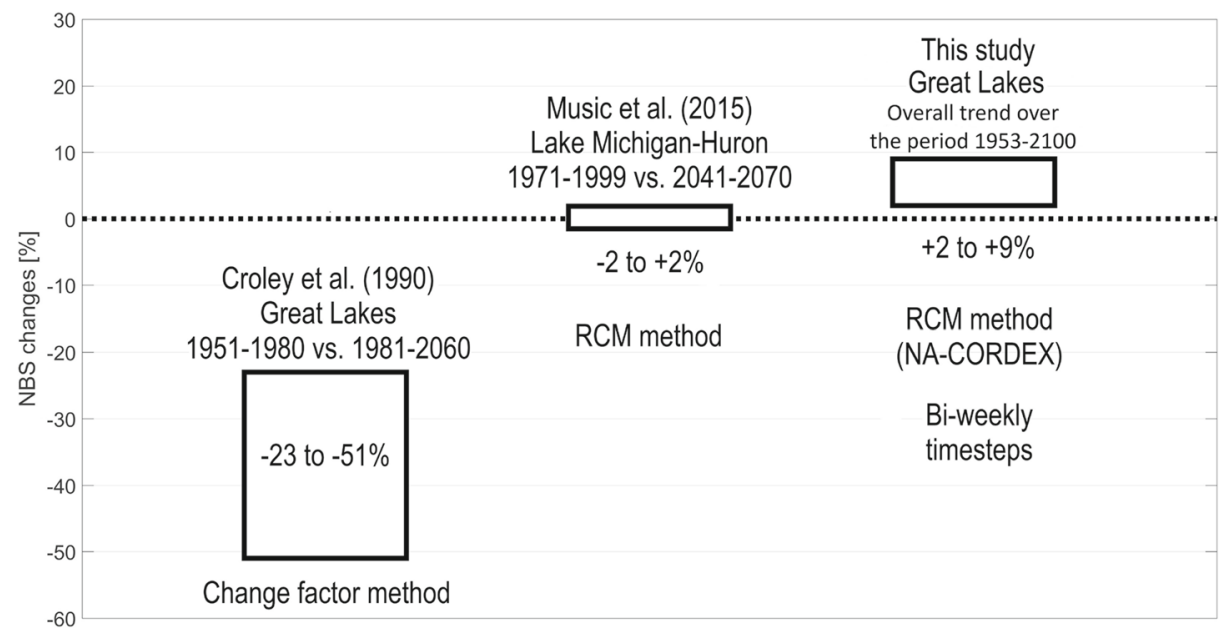

Fig. 6 Comparison of the present study's NBS change results for average conditions with results from two previous studies 
a Minima - Over-lake Precipitation

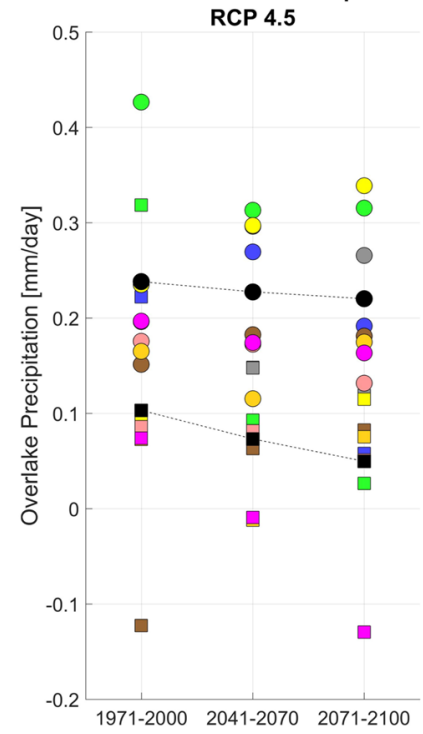

C Minima - NBS - RCP 4.5

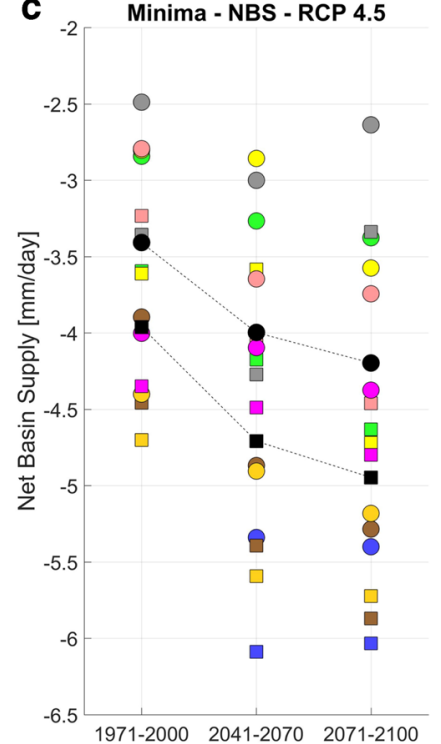

b Maxima - Over-lake Precipitation

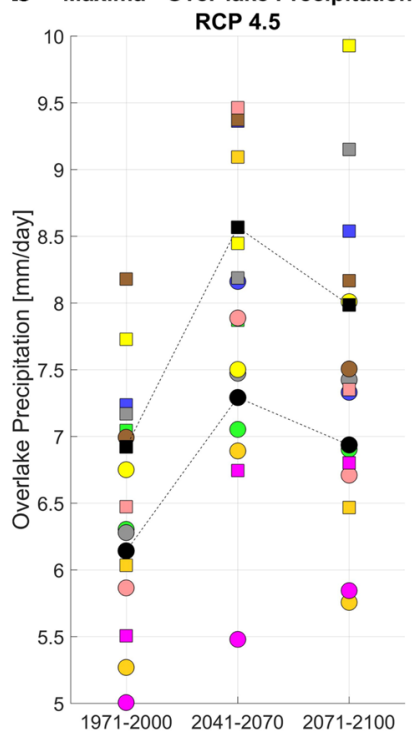

d 22 Maxima - NBS - RCP 4.5

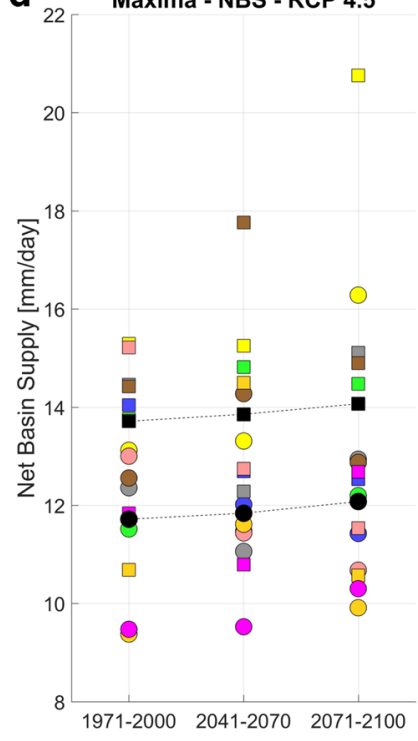

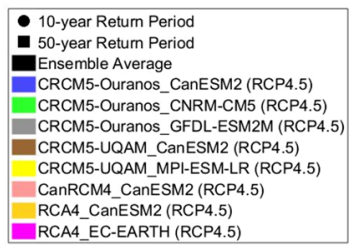

Fig. 7 Evolution of 10 and 50-year return periods values of 14-day (bi-weekly) annual minimum (left) and maximum (right) for over-lake precipitation $(\mathbf{a}, \mathbf{b})$ and NBS $(\mathbf{c}, \mathbf{d})$ for the Great Lakes. Data from scenario RCP4.5 and fitted to a GEV distribution for each period (e.g., 1971-2000) 


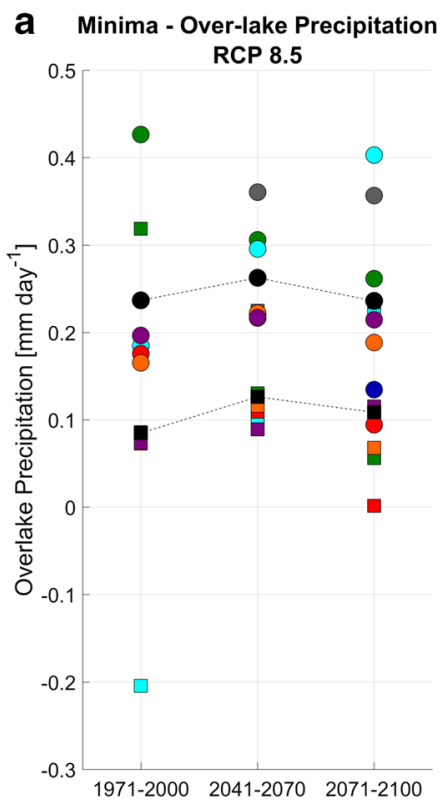

b Maxima - Over-lake Precipitation
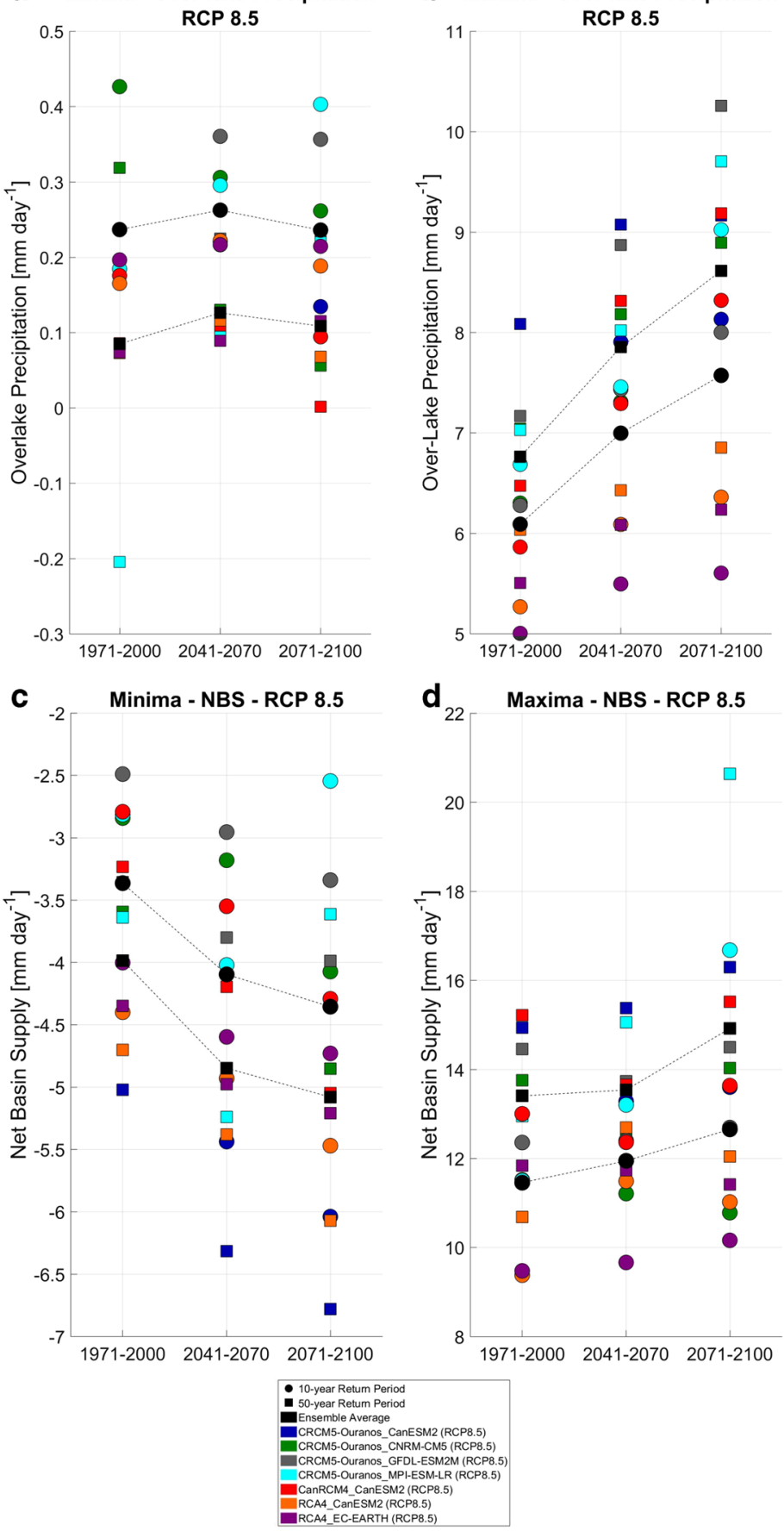

Fig. 8 Evolution of 10 and 50-year return period values of 14-day (bi-weekly) annual minimum (left) and maximum (right) for over-lake precipitation (a, b) and NBS (c, d) for the Great Lakes. Data from scenario RCP8.5 and fitted to a GEV distribution for each period (e.g., 1971-2000) 
Trends of NBS extremes can be compared with Music et al. (2015). NBS annual minima changes between 1971-1999 and 2041-2070 range from -1.8 to $0 \mathrm{~mm} \mathrm{day}^{-1}$ for the 10- and 50-year return periods for the simulations used in the aforementioned study. In comparison, the present paper finds that, for the same periods, NBS minima changes vary between -0.8 and $-0.6 \mathrm{~mm} \mathrm{day}^{-1}$ for the ensembles. Note that changes reported in Music et al. 2015, unlike those obtained in our study, come from individual simulations. For NBS maxima, the results of both studies are less convincing. The increases in this study are quite small (0.1 to $1.2 \mathrm{~mm} \mathrm{day}^{-1}$ for 1971-2000 to 2071-2100) while Music et al. (2015) obtained maximum changes that are unclear due to overlapping confidence intervals.

Results for evaporation and land runoff are not presented in the core of the article, but rather in the Supporting Information document, as the results are not statistically significant.

\section{Concluding remarks}

Several studies have been published in the preceding decades on the issue of climate change impacts on the Great Lakes region. Analyses using the change factor method resulted in projections of important decreases in lake levels (Croley 1990; Hartmann 1990; Angel and Kunkel 2010) while others, using RCMs directly, arrived at lesser declines and even small increases in some instances (MacKay and Seglenieks 2013; Music et al. 2015; Notaro et al. 2015).

Our study is motivated by the availability of new RCM simulations within NACORDEX. Modifications to the RCM's physical parameterizations and an introduction of better performing lake models (Martynov et al. 2013) also testify to the necessity of accomplishing this research. Furthermore, more detailed results are obtained due to changes to this study's methodology when compared with its predecessors that allow analyses of the data on a smaller, two-week, time scale.

Results show small increases in annual NBS from 1953 to 2100 that are not equally distributed throughout the year. Increases in over-lake precipitation and runoff in winter and spring result in positive NBS changes for those seasons while summer is dominated by increased lake evaporation resulting in negative NBS changes. Precipitation and NBS maximum extreme values are projected to grow while negative trends are identified for NBS minimum extremes. Accordingly, an enhancement of the annual cycle of water availability is to be expected for the Great Lakes region during the twenty-first century. No long-term changes can be confidently estimated for lake levels, but their annual cycle will be amplified by climate change.

It will be useful for future studies to explore larger RCM ensembles to better estimate the plausible range of NBS changes. Continued improvements to lake condition representations, among others, are also needed to reduce uncertainty related to model biases. Furthermore, the next logical step for this investigation, though it is out of scope for this paper, would be to extend NBS change results to water levels by running routing models (Clites and Quinn 2003). Thus, research on the topic at hand, with these recommendations, must continue so that decision makers are adequately prepared in the coming years.

Acknowledgments The authors would like to thank Alain Mailhot for his helpful feedback. The CRCM5 data were supplied by Ouranos (CRCM5-O) and by UQAM (CRCM5-U). CRCM5 computations were made on the Guillimin supercomputer from McGill University, managed by Calcul Québec and Compute Canada. The operation of this supercomputer is funded by the Canada Foundation for Innovation (CFI), the Ministère de l'Économie et de l'Innovation du Québec (MEI) and the Fonds de recherche du Québec - Nature et technologies (FRQ-NT). The Canadian Regional Climate Model (CRCM5; Martynov et al. 2013, Separovic 
et al. 2013) was developed by the ESCER Centre at UQAM (Université du Québec à Montréal) with the collaboration of Environment and Climate Change Canada. Data from other RCMs were extracted from the CORDEX database (Mearns et al. 2017). Great Lakes observations were provided by GLERL. This project was funded by Mitacs, the Ouranos consortium and Fonds Vert Québec under grant IT09276.

Open Access This article is distributed under the terms of the Creative Commons Attribution 4.0 International License (http://creativecommons.org/licenses/by/4.0/), which permits unrestricted use, distribution, and reproduction in any medium, provided you give appropriate credit to the original author(s) and the source, provide a link to the Creative Commons license, and indicate if changes were made.

\section{References}

Angel JR, Kunkel KE (2010) The response of Great Lakes water levels to future climate scenarios with an emphasis on Lake Michigan-Huron. J Great Lakes Res 36:51-58

Brown RD, Brasnett B, Robinson D (2003) Gridded north american monthly snow depth and snow water equivalent for gcm evaluation. Atmos-Ocean 41(1):1-14

Christensen OB, Drews M, Christensen JH, Dethloff K, Ketelsen K, Hebestadt I, Rinke A (2006) The HIRHAM regional climate model version 5. Technical Report, pp 6-17

Clites AH, Quinn FH (2003) The history of lake superior regulation: Implications for the future. J Great Lakes Res 29(1):157-171

Croley TE (1990) Laurentian Great Lakes double-CO 2 climate change hydrological impacts. Clim Change $17: 27-47$

Deacu D, Fortin V, Klyszejko E, Spence C, Blanken PD (2012) Predicting the net basin supply to the Great Lakes with a hydrometeorological model. J Hydromet 13(6):1739-1759

Golosov S, Zverev I, Shipunova E, Terzhevik A (1441) (2018) Modified Parameterization of the vertical water temperature profile in the FLake model. Tellus A Dyn Meteo Ocea 70(1):247

Gronewold AD, Clites AH, Hunter TS, Stow CA (2011) An appraisal of the Great Lakes advanced hydrologic prediction system. J Great Lakes Res 37(3):577-583

Gronewold AD, Fortin V, Lofgren B, Clites A, Stow CA, Quinn F (2013) Coasts, water levels, and climate change: a great lakes perspective. Clim Chang 120(4):697-711

Gronewold A, Bruxer J, Durnford D, Smith J, Clites A, Seglenieks F, Qian S, Hunter T, Fortin V (2016) Hydrological drivers of record-setting water level rise on earth's largest lake system. Water Resour Res 52(5):4026-4042

Hartmann HC (1990) Climate change impacts on Laurentian Great Lakes levels. Clim Chang 17(1):49-67

Hayhoe K, VanDorn J, Croley IIT, Schlegal N, Wuebbles D (2010) Regional climate change projections for Chicago and the US Great Lakes. J Great Lakes Res 36:7-21

Kharin VV, Zwiers FW (2005) Estimating extremes in transient climate change simulations. J Clim 18(8):1156-1173

Kupiainen M, Samuelsson P, Jones C, Jansson C, Willén U, Hansson U, Ullerstig A, Wang S, Döscher R (2011) Rossby Centre regional atmospheric model, RCA4. Rossby Centre News

Leung LR, Qian Y, Bian X, Washington WM, Han J, Roads JO (2004) Mid-century ensemble regional climate change scenarios for the western United States. Clim Chang 62:75-113

Lofgren BM, Quinn FH, Clites AH, Assel RA, Eberhardt AJ, Luukkonen CL (2002) Evaluation of potential impacts on Great Lakes water resources based on climate scenarios of two GCMs. J Great Lakes Res 28(4):537-554

Lofgren BM, Hunter TS, Wilbarger J (2011) Effects of using air temperature as a proxy for potential evapotranspiration in climate change scenarios of Great Lakes basin hydrology. J Great Lakes Res 37:744-752

Lofgren BM, Gronewold AD, Acciaioli A, Cherry J, Steiner A, Watkins D (2013) Methodological approaches to projecting the hydrologic impacts of climate change. Earth Interact 17:1-19

MacKay M, Seglenieks F (2013) On the simulation of Laurentian Great Lakes water levels under projections of global climate change. Clim Chang 117:55-67

Martynov A, Sushama L, Laprise R, Winger K, Dugas B (2012) Interactive lakes in the Canadian Regional Climate Model, version 5: The role of lakes in the regional climate of North America. Tellus A 64(1): 16226 
Martynov A, Laprise R, Sushama L, Winger K, Šeparović L, Dugas B (2013) Reanalysis-driven climate simulation over CORDEX North America domain using the Canadian Regional Climate Model, version 5: Model performance evaluation. Clim Dyn 41(11-12):2973-3005

Mearns L, McGinnis S, Korytina D, Arritt R, Biner S, Bukovsky M, Chang HI, Christensen O, Herzmann D, Jiao Y, Kharin S, Lazare M, Nikulin G, Qian M, Scinocca J, Winger K, Castro C, Frigon A, Gutowski W (2017) The NA-CORDEX dataset, version 1.0. https://doi.org/10.5065/D6SJ1JCH, accessed: 201801-14

Mironov D, Kirillin G, Heise E, Golosov S, Terzhevik A, Zverev I (2003) Parameterization of lakes in numerical models for environmental applications. In: Proceedings of 7th Workshop on Physical Processes in Natural Waters, Citeseer, pp 135-143

Music B, Frigon A, Lofgren B, Turcotte R, Cyr JF (2015) Present and future Laurentian Great Lakes hydroclimatic conditions as simulated by regional climate models with an emphasis on Lake Michigan-Huron. Clim Chang 130:603-618

Notaro M, Bennington V, Lofgren B (2015) Dynamical downscaling-based projections of Great Lakes water levels. J Clim 28:9721-9745

Quinn FH (1978) Hydrologic response model of the North American Great Lakes. J Hydro 37(3-4):295-307

Samuelsson P, Kourzeneva E, Mironov D (2010) The impact of lakes on the European climate as simulated by a regional climate model. Boreal Env Res 15:113-129

Scinocca J, Kharin V, Jiao Y, Qian M, Lazare M, Solheim L, Flato G, Biner S, Desgagne M, Dugas B (2016) Coordinated global and regional climate modeling. J Clim 29(1):17-35

Sen PK (1968) Estimates of the regression coefficient based on Kendall's tau. J Am Stat Assoc 63:1379-1389

Šeparović L, Alexandru A, Laprise R, Martynov A, Sushama L, Winger K, Tete K, Valin M (2013) Present climate and climate change over North America as simulated by the fifth-generation Canadian regional climate model. Clim Dyn 41(11-12):3167-3201

Some'e BS, Ezani A, Tabari H (2012) Spatiotemporal trends and change point of precipitation in iran. Atmos Res 113:1-12

Spence C, Blanken P, Lenters J, Hedstrom N (2013) The importance of spring and autumn atmospheric conditions for the evaporation regime of lake superior. J Hydrometeorol 14(5):1647-1658

Theil H (1950) A rank-invariant method of linear and polynominal regression analysis (Parts 1-3). In: Ned. Akad. Wetensch. Proc. Ser. a, vol 53, pp 1397-1412

Tramblay Y, Badi W, Driouech F, El Adlouni S, Neppel L, Servat E (2012) Climate change impacts on extreme precipitation in morocco. Glob Planet Chang 82:104-114

Wilcox RR (2001) Theil-sen estimator: Fundamentals of modern statistical methods. Springer, New York, pp 207-210

Wood AW, Leung LR, Sridhar V, Lettenmaier D (2004) Hydrologic implications of dynamical and statistical approaches to downscaling climate model outputs. Clim Chang 62(1-3):189-216

Xue P, Pal JS, Ye X, Lenters JD, Huang C, Chu PY (2017) Improving the simulation of large lakes in regional climate modeling: Two-way lake-atmosphere coupling with a 3D hydrodynamic model of the Great Lakes. J Clim 30(5):1605-1627

Zhao G, Hörmann G, Fohrer N, Zhang Z, Zhai J (2010) Streamflow trends and climate variability impacts in poyang lake basin, china. Water Resour Manag 24(4):689-706

Publisher's note Springer Nature remains neutral with regard to jurisdictional claims in published maps and institutional affiliations. 